\title{
BEM EGOLÓGICO E BEM COMUM: ENTRE ANTIGOS E HELÊNICOS
}

\author{
Ana Rosa Luz ${ }^{1}$ \\ Universidade do Estado do Rio de Janeiro (UERJ) \\ https://orcid.org/0000-0001-8476-6481 \\ E-mail: luz.anarosa@yahoo.com.br
}

\section{RESUMO:}

$O$ artigo que se apresenta tem por objeto central ser um atravessamento entre as noções de bem comum e bem individual. Assim, pretendeu-se desenvolver a explicação do percurso histórico-filosófico, de onde se deu a passagem e interposição entre as concepções éticas de bem comum e bem individual; no que diz respeito, do mesmo modo, à passagem entre a antiguidade grega e o mundo helênico. Por conseguinte, o presente escrito tratar-se-á da apresentação de um panorama geral de transposição teórica e de concepção política, quando na emergência do desenho arquitetado por certos filósofos que se mostram fundamentais à questão política antiga e helênica. A saber: Platão, Aristóteles, Epicuro, Zenão de Cítio e Pirro. Pensadores fundadores do entendimento sobre o que seja a política, de modo atemporal; sendo, por este motivo, eles mesmos a arche e ponto de partida de qualquer investigação sobre o é determinado enquanto ethos humano, inserido nesta perspectiva nascente e corrente que denominamos de busca por um bem egológico.

PAlaVRaS-CHAVE: Bem; Ethos; Política; Antiguidade; Helenismo.

\section{EGOLOGICAL AND COMMOM GOODS: BETWEEN ANCIENT AND HELLENIC}

\begin{abstract}
:
The article that is presented has as its main object to be a crossing between the notions of common good and individual good. Thus, it was intended to develop the explanation of the historical-philosophical path, from where the passage and interposition between the ethical conceptions of common and individual goods took place; with regard, likewise, to the passage between Greek antiquity and Hellenic world. Therefore, the present writing will deal with the presentation of a general panorama of theoretical transposition and political conception, when in the emergence of the design architected by certain philosophers who prove to be fundamental to the ancient and Hellenic political question. Namely: Plato, Aristotle, Epicurus, Zeno of Citium and Pyrrhus. Founding thinkers of the understanding of what politics is, in a timeless way; for this reason, they themselves are the arche and starting point of any investigation of what is determined as a human ethos, inserted in this nascent and current perspective that we call the search for an ego-good.
\end{abstract}

KEYWORDS: Good; Ethos; Politics; Antiquity; Hellenism.

\footnotetext{
${ }^{1}$ Doutor(a) em Filosofia pela Universidade do Estado do Rio de Janeiro (UERJ), Rio de Janeiro - RJ, Brasil. Professor(a) de Filosofia da Universidade do Estado do Rio de Janeiro, no Instituto de Aplicação Fernando Rodrigues da Silveira (CAp-UERJ), Rio de Janeiro - RJ, Brasil.
}

LUZ, Ana Rosa. Bem egológico e bem comum: entre antigos e helênicos. Griot : Revista de Filosofia, Amargosa - BA, v.22 n.1, p.1-11, fevereiro, 2022. 
De modo a introduzir o presente texto e dar conta dos problemas levantados pelo tema a ser trabalhado - a saber, a questão ética e política de diferenciação entre o bem egológico e o bem comum na grega clássica e no Helenismo -, procuraremos elaborar um percurso históricofilosófico, de modo a clarificar as mudanças dos polos de pensamento referentes a cada época. Para tanto, em primeiro lugar, buscaremos explicitar o sentido etimológico dos termos ética e política, para que em seguida seja possível construir um breve arcabouço teórico tanto na Grécia antiga quanto no período no Helenismo. De modo, então, a embasar a temática a ser construída, elencaremos como bases incontornáveis de desenvolvimento sobre a questão supracitada: Platão, Aristóteles, a filosofia estoica e pirrônica. Cujos pensamentos permitem observar claramente como ocorreu a passagem entre a ética do bem comum grega antiga e a ética individualista helênica. Sendo assim, de maneira a não nos alongarmos mais, partamos à contextualização etimológica indicada.

Em seu sentido originário, o termo ética (ethike) é tudo aquilo o que se refere ao hábito (ethos), ou seja, ao modo de ser e agir do homem. Logo, por definição terminológica, a ética é a investigação sobre as ações humanas. $O$ campo de reflexão que investiga a intencionalidade das ações, as escolhas práticas deliberadas referentes aos propósitos que levam o homem a agir. Indo além desta concepção etimológica, na compreensão atual e usual do termo encontramos a seguinte definição elaborada por Ferreira (1993, p.235): a ética é o "estudo dos juízos de apreciação referente à conduta humana, do ponto de vista do bem e do mal". Não muito distante da concepção grega, assim como é definida hoje, a ética também é compreendida como sendo algo relativo às ações humanas, a sua conduta enquanto tal. Esta segunda definição, apresenta, entretanto, um segundo elemento conceitual que não é explicitado no seu sentido originário, a ética além de ser acerca das ações humanas, ela é referente à escolha, ou seja, à deliberação que leva o homem a agir bem ou mal. Nas palavras de Luz (2018, p.1):

Tal como é teorizado por Aristóteles, na Ética a Nicômaco, a ética é “uma capacidade verdadeira e raciocinada de agir com respeito às coisas que são boas ou más para o homem"(ARISTÓTELES, 1140b). Ora, assim como visto nas definições acima, a ética trata essencialmente da ação humana, ou seja, ela trata dos atos ou ações próprias de cada homem. Lida com o cuidado humano em tomar boas decisões e, por conta disso, realizar boas ações. Sendo assim, a ética investiga o bem humano enquanto tal, e mais, tal como explicita Aristóteles, no âmbito da ética o homem não tenta ser apenas bom, ele tenta ser excelente ou virtuoso a partir da prática de suas ações (LUZ, 2018, p.1).

À vista disto, o termo ética tem a ver como o modo de vida dos indivíduos, com a formação e criação do seu caráter fundamentado nas suas ações. Desta maneira, é possível dizer que a ética tem relação com a formação de hábitos práticos. Ou ainda, em termos gregos, a ética é a ciência do ethos (hábito), já que se define a partir da repetição das ações humanas que corroboram para a formação do caráter. Mas, afinal, o que significa dizer que a ética é a ciência do ethos? Do grego antigo, o termo ethos significa hábito, costume, uso, hábito social ou político, habitualmente, ter hábito de ${ }^{2}$. Sendo assim, esta compreensão etimológica da origem do termo ética, acaba por confirmar a sua ligação irremediável com o hábito, com a formação de costumes que, assim como veremos, está diretamente relacionada à formação de caráter.

Cabe ressaltar, ainda, que o homem grego não fazia uma distinção clara entre ética, política e moral. Por isso, falar sobre ética na Grécia Antiga significa que a política e a moral se encontram interpostas e entrelaçadas a ela, na teorização filosófica desenvolvida. Isto, porque quando Platão e Aristóteles estão a arquitetar suas reflexões éticas, como por exemplo, eles

${ }^{2}$ Cf. BAILLY (1950, p.247). 
também estão explicitando suas teorias políticas e morais. Visto que, para o homem grego, formar o seu ethos é equivalente a sua formação política e moral. Sendo assim, sigamos com a definição etimológica de política para que, em seguida, adentremos em nosso escopo teórico. Em seu sentido originário, o termo política (politike) significa a técnica (techne) de governar a polis. Trara-se, portanto, daquilo que se refere ao poder e suas relações - definição esta observável no próprio desmembramento do termo polikratia (que deriva a palavra politike, cujo prefixo advindo de techne pressupõe já uma atividade prática), o poder (kratos) da polis.

Apreendidas, então, as significações primárias dos termos ética e política, abordemos as perspectivas platônicas e aristotélicas que, como veremos, constituem o nascimento efetivo, irremediável e fundamental da filosofia política antiga.

A ética e a política nasceram, enquanto polos de problematização filosófica e não enquanto instâncias humanas, por volta dos séculos V e IV a.C. na Grécia Antiga, tendo Platão como seu filósofo fundador. Mas por que Platão e não Sócrates? Ora, de modo a clarificar o próprio desenvolvimento das questões a serem apresentadas, é imperativo que se distinga o Sócrates histórico do Sócrates personagem dos diálogos de Platão. Tal como é sabido, o Sócrates histórico nada escreveu. Fazendo com que as suas reais reflexões filosóficas sejam de difícil identificação - problema este massivamente tratado pelos pesquisadores contemporâneos da área. Sendo assim, ao tratarmos do emergir filosófico ético-político, faremos referência à obra platônica e, quando citarmos Sócrates será sempre em relação ao personagem dos diálogos de Platão e não ao Sócrates histórico, cujo qual sabemos, enquanto comunidade científica, tão pouco.

Destarte, retomando o problema central do presente texto, reitera-se que foi com Platão que a conduta prática e a formação do ethos humano se tornaram foco de problematização na Grécia Antiga. Ora, enquanto os filósofos da physis se preocupavam, sobretudo, em refletir acerca das coisas primeiras do cosmos, estando estas externas ao homem; Platão se empenhou em mudar a esfera de pensamento, trazendo o polo de reflexão para o próprio homem - seu comportamento prático e modo de pensar. Sendo a partir do problema da busca pelo conhecimento verdadeiramente existente (as Ideias), que o filósofo funda sua tese acerca da praxis humana.

Com efeito, é na República que podemos identificar a ética platônica de maneira mais evidente. Entretanto, antes de adentrarmos propriamente na teoria política desenvolvida na obra, é relevante dizer que já no Górgias (XIX) - obra anterior à República -, Platão apresenta sua hipótese suprema, onde a política é definida como uma techne que é diretamente relacionada à natureza da alma - não desenvolvendo, entretanto, esta teoria a fundo. Assim, é na República que Platão desenvolverá a tese exposta, cujo objetivo é utilizá-la como um referencial argumentativo para a construção de sua teoria da reminiscência.

No Livro I da República, então, Platão afirma que antes de teorizar sobre qualquer coisa propriamente humana - afirmação esta que é recorrente na maioria dos seus diálogos - é preciso que se conheça a natureza da alma. Pois só a partir do conhecimento da psyche e sua estrutura interna, que é possível identificar a virtude (arete) inerente a cada indivíduo, como seu ethos é formado e qual o seu papel perante a sociedade.

Mas o que vem a ser a virtude para Platão e qual a sua relação com a natureza da alma? De acordo com o filósofo, a arete é uma disposição da alma, que faz com que o homem aja de uma certa maneira. Assim, cada homem teria uma função que lhe é própria, uma virtude que permitiria desempenhar uma função com excelência. Ora, mas como distinguir qual a função ou virtude próprias de cada indivíduo? Bem, partindo do pressuposto de que as virtudes são 
internas à estrutura da alma humana, todos os homens buscariam, de maneira inata, um tipo específico de bem. Sendo este condizente com a sua função específica.

Deste modo, nos Livros II e III da República, Platão se ocupará de diferenciar os tipos de bens existentes, para que depois venha a desenvolver, a partir deles, sua cidade ideal que, como veremos, se baseará na noção de virtude. Isto posto, o filósofo afirma que existem três tipos de bem: (1) os bens não necessários, desejados por eles mesmos de forma imediata, inata e não liberada (tal como a satisfação dos apetites); (2) os bens intermediários, que só são desejados pelas suas consequências (tal como a saúde); (3) e os bens necessários, desejados por eles mesmos e por suas consequências (tal como a sabedoria e a justiça).

De acordo com Platão, então, cada homem tende a valorizar em um grau superior um destes bens, de acordo com a natureza da sua alma, o que definiria, por consequência, a sua função na polis. Segundo o filósofo, todos os bens supracitados são importantes ao equilíbrio da cidade. E considerando que cada homem só valoriza um tipo de bem, Platão conclui que nenhum homem é autossuficiente. Todos os homens devem viver em sociedade, na medida em que, por priorizar um só bem, temos mais necessidades do que capacidade para satisfazê-las. Logo, a vida em sociedade é fonte de satisfação das necessidades comuns, visto que, de acordo com o bem que é privilegiado é possível que se dividam as atividades ou funções (arete) individuais, tendo em vista o bem comum.

Partindo da asserção desta tríplice de bens, então, Platão fundará a sua teoria da tripartição da alma. Afirmando ser esta a base da construção de uma cidade justa (dikaiopolis), onde todas as necessidades humanas seriam saciadas. Assim, tal como diz o filósofo, a alma humana é dividida em três partes. E a predominância de uma destas partes em cada indivíduo formaria uma virtude, um tipo de homem e um tipo de bem específicos. Deste modo, inserindo o predomínio de uma das partes da alma na formulação da cidade ideal platônica, tal como em uma pirâmide, teríamos em sua base a alma epithymênica. Este tipo de alma, cujos apetites (epithymia) se sobrepõem às outras partes, tem por virtude os impulsos inatos e, por isso, tem o epithymetikon como o tipo de homem - aquele que por ser guiado pelos apetites não deliberados, e almejar os bens não necessários, é responsável pelos trabalhos físicos e manuais da polis. Em segundo lugar, estando no meio da pirâmide, temos a predominância da parte da alma referente ao thymos. Onde também impera o apetite (epithymia; que tem o termo thymos como raiz etimológica). Entretanto, neste tipo de alma há um desejo mais deliberado, fazendo com que suas virtudes se configurem como um impulso dos afetos, a cólera (hybris) e a coragem (andreia); e o tipo de homem referente a ela o thymolides - aquele que é guiado pelos afetos e almeja os bens intermediários - representado pelos guerreiros. Por fim, no topo da pirâmide há a alma cuja parte predominante é o logos (razão, discurso, linguagem, palavra, conhecimento), que tem por virtude a racionalidade e a busca eterna pelos conhecimentos verdadeiramente existentes. $\mathrm{O}$ tipo de homem derivado da supremacia do logos sobre as demais partes da alma é o logistikon, representado pelos filósofos. Dado que os filópsofos são os únicos guiados pela razão e preza pelos bens necessários. Quer dizer, nas palavras do filósofo: por uma classe de bens "que nos agradamos tanto por eles mesmos como por suas consequências" (357b).

Nesta estrutura de pirâmide, então, Platão acaba por construir um sistema sophokratico, onde a alma cuja racionalidade é dominante deve se sobrepor e governar os outros tipos de alma. Visto que só o logistikon possui a arete suprema da justiça, resultante da busca incessante pelo conhecimento, ele se apresenta como o único capaz de promover o bem comum desta polis distópica platônica. Em contrapartida, nesta dinâmica aristocrática - que no próprio sentido etimológico do termo significa o poder dos melhores -, na construção desta cidade ideal, Platão afirma ser imperativo que todos os cidadãos sejam felizes de maneira igual. Logo, o exercício da 
função (arete) própria de cada um é diretamente relacionado ao bem comum, resultado direto da harmonia entre a tríplice de bens supracitada.

Definidos, então, os pressupostos ético-políticos platônicos caros a nós, partamos à análise da filosofia aristotélica, observando de que modo ela se distancia ou congrui com o pensamento de Platão, partindo desta visão sophokratica em prol do bem comum.

Tal como o descrito, Platão foi o fundador da reflexão ético-política na Grécia Antiga. Em contrapartida, o filósofo tinha como preocupação central a defesa da teoria das Formas, fazendo com que o seu estudo acerca da praxis humana servisse apenas de embasamento à reminiscência. Sendo assim, é possível afirmar que Aristóteles foi o primeiro filósofo a formular de maneira efetiva um tratado normativo ético-político. Em A Política e na Ética a Nicômaco, o filósofo se propõe a investigar acerca da intencionalidade das ações humanas. Tendo como ponto base a forma com que o homem deve agir para poder viver de maneira excelente e, assim, promover o bem comum. Vejamos, então, certos aspectos relevantes das obras citadas, de modo a criarmos um panorama conceitual sobre o que dominaremos de ética das virtudes aristotélica. Deste modo, em primeiro lugar, é de extrema importância que analisemos como Aristóteles define o homem nos livros iniciais de $A$ Política.

A Política tem como um de seus objetivos primários falar sobre o status do homem, enquanto ser naturalmente político, a partir da função que o difere dos outros animais: a fala e a deliberação - que estão intimamente relacionadas, sendo consideradas como um único elemento. Para além disto, em $A$ Política Aristóteles se preocupa em apresentar as formas possíveis de governo (monarquia, aristocracia, democracia e oligarquia), contrapondo-as uma a uma até chegar a conclusão do porquê a democracia ateniense é a melhor forma de governo e a que melhor pode levar o homem à felicidade.

De acordo com o filósofo, então, o homem se define através das duas funções inatas que possui. A saber, o homem é, por natureza, um zoon logistikon (animal racional) e um zoon politikon (animal político). Sendo assim, tal como é afirmado, o logos é algo sem o qual o homem não seria homem. Sendo justamente a faculdade racional e dialógica (referente à linguagem) que difere o homem dos outros animais. Em outras palavras, enquanto os outros animais respondem apenas a instintos de sobrevivência inatos, o homem é dotado de fala e deliberação (logos), sendo justo por isto que ele tem como inata a habilidade política. Em suas palavras:

\footnotetext{
Agora é evidente que o homem, muito mais que a abelha ou outro animal gregário, é um animal político. Como costumamos dizer, a natureza nada faz em vão, e o homem é o único entre os animais que tem o dom da fala. Na verdade, a simples voz pode indicar a dor e o prazer, e outros animais a possuem (sua natureza foi desenvolvida somente até o ponto de ter sensações do que é doloroso ou agradável e externa-las entre si), mas a fala tem a finalidade de indicar o conveniente e o nocivo, e portanto também o justo e o injusto; a característica específica do homem em comparação com os outros animais é que somente ele tem o sentimento do bem e do mal, do justo e do injusto e de outras qualidades morais, e é a comunidade de seres com tal sentimento que constitui a família e a cidade (ARISTÓTELES, $A$ Política, 1253a).
}

Portanto, o homem é compreendido como destinado, naturalmente, a fazer política; sendo exatamente o logos que o diferencia dos outros seres vivos. Os animais não são seres político, nem o podem ser, pois não compartilham da palavra ou argumentação e da deliberação. E se assim como acreditava Aristóteles, a natureza nada faz em vão, e se ela deu ao homem o poder da palavra e da deliberação, ele pode ser dito como sendo naturalmente um animal político. 
Por ser dotado de fala e deliberação, o homem é um ser ético-político. Por isso, ele deve alcançar a plenitude, o seu fim último, o bem supremo para a vida, através desta habilidade particular. A única forma de exercer plenamente a humanidade é estando com os outros, é vivendo em sociedade. Logo, um homem só é pleno quando se faz ético e político. Isto é, quando não está sozinho ou inserido em uma estrutura social.

Ora, se o homem é naturalmente um ser político, não é possível que ele viva bem vivendo só. É necessário que o homem viva em uma comunidade. De acordo com Aristóteles, o homem fora da vida em sociedade deixa de ser homem. Se a função do homem é viver em sociedade e, deste modo, deliberar acerca de suas ações, se ele viver sozinho ele não cumpre a sua função. E, assim como afirma o filósofo, uma coisa, qualquer que seja, só pode ser denominada enquanto tal se ela realiza bem a função que lhe é própria. E sendo um homem um animal político, sendo esta a sua função, se ele não o for, ele deixa de ser homem. Da mesma maneira, a humanidade só se caracteriza como humanidade pelo fato do homem ser político, pois é por causa desta natureza, ou função natural, que ele é capaz não só de viver sob leis e regras, mas também de cria-las para si. Viver, portanto, significa promover a manutenção do bem comum. E se o homem é por natureza um animal político, é para que ele possa viver bem, para que ele possa viver da melhor maneira possível.

A política para Aristóteles não é um ato de volição, não podemos nos eximir dos fins políticos. Isto se confirma, na medida em que se pensa na vida em sociedade como um todo. Em todos os ambientes que nos circundam, mesmo que seja um ato involuntário, há a formação de uma relação política, ou ainda - apesar de não estar nas bases teóricas de Aristóteles (sendo abordado apenas a partir dos filósofos modernos) -, de um contrato social. No interior da instituição familiar, há certas regras normativas que, mesmo que não sejam escritas, configuram legitimamente um contrato social. Da mesma maneira acontece em todas as instituições que compõem uma sociedade, independente do seu tempo ou contexto cultural. Todos os homens naturalmente mantêm relações políticas para que ele possa viver e, mais que isso, para que ele possa viver bem, de forma excelente. A sociedade é, portanto, formada por um pacto entre indivíduos, para que eles possam viver plenamente, para que eles possam viver da melhor maneira possível. Sendo assim, é legítimo que se afirme que, sim, o homem é por natureza um ser político. Em termos gregos, o homem é um zoon politikon (do grego, animal político), por pertencer naturalmente à vida em sociedade.

O homem, portanto, é dotado de racionalidade, e mais, o homem é dotado de fala, o que o torna, por natureza, um animal político. Visto que ele tem como instrumento fundamental a deliberação, a capacidade de raciocínio e escolha que interferem invariavelmente no seu modo de agir em sociedade. Compreender esta racionalidade, esta função particular do homem, é essencial para que se possa entender a felicidade, visto que o princípio racional que rege as atitudes e o pensamento humanos constitui a natureza da própria felicidade.

Partindo da definição da natureza humana, então, Aristóteles se questiona acerca do modo como é possível se exercer a função que nos é inata. A saber, a vida em sociedade. Ora, o homem só vive de forma plena se ele exerce a sua função e a desenvolve. Ou seja, ele só se faz enquanto homem sendo um ser ético-político. Tal como afirma Aristóteles: viver é estar entre os homens, e deixar de viver é deixar de estar entre os homens. Se o homem não exerce a sua função política, ele deixa de ser homem. E exercer a sua função significa deliberar sobre as próprias ações, de modo a possibilitar a vida em sociedade e promover o bem comum.

Na esteira deste pensamento, partindo do conteúdo da Ética a Nicômaco, Aristóteles passa a se questionar sobre a natureza e os objetivos das ações humanas. Baseando-se em uma concepção teleológica, cujo objetivo é o estudo da finalidade última da praxis humana; o filósofo 
arquiteta uma ética das virtudes, afirmando ser a felicidade o sumo bem de toda a vida e o objetivo supremo da conduta prática. Assim, ao longo da Ética, Aristóteles terá a preocupação de apresentar quais as práticas mais valorosas que permitiriam o homem a alcançar a felicidade e, por consequência, o bem comum da polis. De acordo com os princípios aristotélicos, então, a felicidade só pode ser alcançada através de uma vida de virtudes (arete). Onde a sabedoria prática (phronesis) e a mediania moral se mostram como elementos essenciais para se alcançar o Sumo Bem da vida humana. Tal como é colocado, só com uma vida plena de virtudes, só com ações excelentes (arete), só com a formação de bons hábitos (ethos), e consequentemente de um bom caráter, que o homem consegue atingir a felicidade e, assim, exercer de forma plena suas funções inatas. Logo, para Aristóteles, exercer as funções que nos são inatas com sabedoria prática e medida é promover não só o nosso bem particular como também o bem comum. Cabendo a um bom governante, tão somente promover as condições necessárias para que os seus cidadãos consigam alcançar o sumo bem de maneira equivalente.

Concluindo este seguimento argumentativo acerca do pensamento aristotélico, é possível afirmar que Platão e seu discípulo em muito dialogam a respeito dos objetivos essenciais de uma polis. Apesar de em muito divergirem em termos estruturais reflexivos, ambos concordam que o logos configura a parte inata mais importante do homem, que em uma sociedade ideal todos os cidadãos devem ser igualmente felizes e que toda praxis humana deve convergir sempre ao bem comum.

Sendo exatamente estas três proposições que configurarão o ponto de ruptura entre a reflexão ética grega antiga e a helênica.

Isto posto, antes de adentrarmos na estrutura teórico-filosófica da época helênica, façamos uma breve contextualização que em muito clarificará a mudança dos polos de reflexão ético-políticos.

No século III a.C., as grandes expedições de Alexandre Magno marcam o fim de uma época, tanto histórica quanto filosófica, tendo como consequência uma reviravolta radical do espírito reflexivo grego antigo. Tal como veremos a seguir, o seu projeto de monarquia divina universal e de sincretismo cultural configura um golpe mortal para a antiga concepção de cidade-estado grega. Como por exemplo, realizando um retorno à Grécia Antiga, Atenas era vista como cidade-estado, cujos cidadãos participavam ativamente da vida pública. Não havia qualquer heterogenia cultural e a formação era dada exclusivamente para a polis, a partir de uma ética do bem comum - tal como foi possível observar em Platão e Aristóteles. Destarte, com as conquistas de Alexandre, que funda o Helenismo (que em sua etimologia significa viver ou falar como os gregos), não existe mais a noção de uma cidade-estado. Portanto, através do sincretismo cultural alexandrino a polis é transformada em cosmopolis (cidade do mundo) e o politos (cidadão), por sua vez, se torna um cosmopolita (cidadão do mundo) que, por conta do final do sistema democrático e da reascensão da monarquia, perde sua principal referência política. Logo, não havendo mais atividade política, o homem passa a se formar enquanto sujeito individualizado, dentro de uma perspectiva egológica do conhecer e do fazer político que se encontra diminuído. Formação esta que o fará procurar bens igualmente individuais. Em outras palavras, longe das discussões políticas, o homem não se preocupa mais com a ação efetiva na e pela polis, em prol do bem comum, se descobrindo enquanto indivíduo.

Tendo como centro de mudança estrutural da conduta humana tais acontecimentos históricos, novos modelos de vida são propostos por uma filosofia emergente que não visam mais, como o dito, a procura de um bem comum coletivizado, e sim a procura de um bem individual, onde o ethos é voltado para um desenvolvimento essencialmente autárquico, e cuja preocupação principal era, sobretudo, estabelecer as regras para o bem viver, a partir da

LUZ, Ana Rosa. Bem egológico e bem comum: entre antigos e helênicos. Griot : Revista de Filosofia, Amargosa - BA, v.22 n.1, p.1-11, fevereiro, 2022. 
tentativa de se encontrar a fórmula para a felicidade - sob pressupostos acríticos e baseados essencialmente platônicos e aristotélicos. Então, como principais representantes desta nova reflexão temos: o epicurismo, o estoicismo, o Pirronismo e o cinismo. Entretanto, para uma explicitação mais breve da filosofia ético-política helênica, nos ateremos a trabalhar tão somente como as primeiras três correntes citadas.

A primeira das grandes escolas helenísticas foi a de Epicuro, que surge em Atenas por volta do fim do século IV a.C. Sua filosofia hedonista tinha como base a busca pelo prazer e a supressão da dor. Em suas palavras: "todo prazer constitui um bem por sua própria natureza" (EPICURO, 2002, p.39). Segundo o filósofo, entretanto, a satisfação dos prazeres não pode ser dada de maneira ilibada. Os prazeres devem ser submetidos ao comedimento (metron), sendo serenos e calmos. Visto que os prazeres muito intensos podem trazer perturbações à alma. Ou seja, apesar de realizar uma ética dos prazeres, Epicuro defende que estes devem sempre ser medidos pelo logos, pelo metron e pela phronesis (sabedoria prática). Afirmando, da mesma maneira, que o fim último da praxis humana é a felicidade, o filósofo diz que esta só pode ser alcançada através da tranquilidade da alma, ou ainda, através de um estado de imperturbabilidade da psyche (ataraxia).

Na construção do homem autárquico helênico, então, a busca por uma felicidade egocentrada se faz imperativa. E para que ela seja alcançada é preciso, enquanto princípio ético epicurista básico, liberdade (para que a alma permaneça serena), amizade (para que seja possível a troca de conhecimento e compartilhamento de prazeres) e filosofia (pois a busca pelo conhecimento verdadeiro é essencial para uma vida feliz). Sobre a filosofia, Epicuro ainda nos diz:

Que ninguém hesite em se dedicar a filosofia enquanto jovem, nem se canse de fazê-lo depois de velho para alcançar a saúde do espírito. Quem afirma que a hora de dedicar-se a filosofia ainda não chegou, ou que ela já passou, é como se dissesse que ainda não chegou ou que já passou a hora de ser feliz (EPICURO, 1973, p.21-3).

Em retorno: tal como ocorre em toda filosofia helenista, o homem não se compreende mais como um ser inserido e indissociável da vida pública. Surge, deste modo, uma nova sensibilidade reflexiva, em que para atingir a felicidade, o homem só precisa de si mesmo. $\mathrm{O}$ hedonismo de Epicuro irá, então, se contrapor diretamente à noção platônica de que os prazeres imediatos e inatos (epithymia) seriam a parte mais baixa da alma, tendo, portanto, de ser moderados. Indo pelo caminho oposto, o epicurismo defenderá que os apetites inatos do prazer, o desejo dos sentidos são os guias para o verdadeiro. Enquanto Platão se preocupa em defender uma vida voltada para o bem comum, para a justiça e para uma realidade transcendental, os epicuristas têm como paradigma a afirmação da vida através da efetuação mesma dos prazeres individuais terrenos, tendo como pressuposto que só estes podem levar ao estado de imperturbabilidade da alma (ataraxia).

Dando prosseguimento, ao que concerne a filosofia estoica, cabe ressaltar que, tal como no epicurismo, os filósofos desta corrente também negavam a noção transcendental de mundo platônica. Para os estoicos, a filosofia também deveria ser considerada como a techne de viver, e também deveria ter como base os sentidos, a experiência do vivido. Entretanto, o estoicismo não tinha o hedonismo como fundamento da conduta prática humana. Nas palavras de Abrão (2004):

[...] para os estoicos, a felicidade consiste em viver de acordo com essa ordem universal, permanecendo indiferente aos males, que não passam de aspectos isolados no todo 
racional. Viver de acordo com a razão significa desviar-se das paixões, que são as perturbações da razão (ABRÃ̃, 2004, p.75).

Com efeito, os estoicos foram os primeiros pensadores a se reconhecer enquanto cidadãos do mundo, sendo inclusive os criadores dos termos cosmopolis e cosmopolita. Assim, segundo a ética estoicista, a experiência individual deve ser tomada como base de todo o conhecimento. Dado que, tal como defendia Zenão de Cítio (336 a.C. - 264 a.C.), filósofo epicurista, por serem cidadãos do mundo, os homens deve se seguir pelas leis do gênero humano. Quer dizer: reconhecer ser a lei natural enquanto lei do homem. Uma lei ética que deve se sobrepor e antever a qualquer lei política. Nas palavras de Gazolla (1999, p.62): "a norma natural é a norma ética". Ainda em suas palavras:

[...] anterior a ser grego, fenício ou espartano, e o que o essencial e ser cosmopolita, cidadão do mundo, o que significa desconsiderar os limites geopolíticos traçados pela historicidade. Deve-se atentar bem mais à consonância com a physis que construiu o modo de ser humano originário do que as regras mutáveis erigidas [...] (GAZOLLA, 1999, p.50).

Logo, tendo a ética como fatia mais importante de seu pensamento, os estoicos têm por objeto de estudo a techne de bem viver, onde o indivíduo passa a se desenvolver como pessoa singular. Tal como é defendido por Aristóteles - assim como também fazem os epicuristas -, para os estoicos o objetivo da vida humana e seu princípio ético supremo é a felicidade. Felicidade esta que só pode ser alcançada através de um estado de imperturbabilidade da alma (ataraxia) - teoria que percorrerá todas as correntes filosóficas helênicas. Entretanto, segundo os estoicos, a ataraxia só pode ser alcançada com metron, logos e com a aceitação do curso do destino - que acaba por desencadear um determinismo ético fatalista.

Tal como o colocado acima, a despeito dos epicuristas, os estoicos não tem o prazer (hedone) como princípio ético. Ao contrário, o pathos advindo dos prazeres é fonte de perturbação para a alma. Por ser da ordem do irracional, as paixões são consideradas como um mal, fruto de um erro de julgamento. Logo, elas devem ser extintas, fazendo com que a filosofia estoica seja rotulada como contendo uma apathia extrema, nessa dinâmica da não-emoção, da não-sensação.

Tendo estabelecido os princípios éticos epicuristas e estoicistas, sigamos, por fim, à apresentação breve de dois aspectos da filosofia de Pirro - filósofo helênico de grande relevância, justo por ser o fundador do pensamento cético.

A filosofia pirrônica tinha como foco central a investigação acerca da legitimidade do real (da natureza das coisas), como o homem deve agir frente a esta realidade e quais as consequências desta ação. Tais proposições já permitem identificar a essencialidade prática da filosofia de Pirro, tal como se configura todo pensamento helênico. Em contrapartida, segundo o filósofo nem os sentidos nem a razão nos permitem conhecer as coisas tal como elas são. Logo, todas as tentativas de apreensão de algum conhecimento verdadeira resultariam em fracasso. Por isso, Pirro afirma que: como não podemos ter conhecimento das coisas é preciso se distanciar delas, pois a tentativa inútil de conhecer só traria perturbações para a alma. E tal como ocorre em toda filosofia helênica, os princípios ético fundamentais para a filosofia pirrônica é a ataraxia, seguida da apathia (tal como no estoicismo) e da aproxia (inação). Só através destes princípios que é possível chegar ao objetivo supremo da vida humana: a felicidade. Vejamos o que é exposto por Sexto Empírico, a este respeito: 
O ceticismo é uma habilidade que opõe as coisas que aparecem e que são pensadas de todos os modos possíveis, com o resultado de que devido a equipolência nesta oposição tanto no que diz respeito aos objetos quanto às explicações, somos levados inicialmente à suspensão [epoche] e depois à tranquilidade [ataraxia $]^{3}$ (SEXTO EMPÍRICO, 1997, p.116).

O ceticismo pirrônico tem, deste modo, por objeto central, a epoche e a ataraxia radizalizadas. Nas palavras de Luz (2021, p.202): de acordo com Pirro, "o cético seria aquele que se perturba diante de alguma irregularidade das coisas, passando, por isso, a investigar acerca da verdade sobre elas; para que, então, possa alcançar a tranquilidade da alma (ataraxia)". Sendo que esta tranquilidade, "a ataraxia só se faz possível via epoche".

De modo a concluir o presente texto, é possível afirmar que tanto a filosofia grega clássica quanto a filosofia helenista em muito nos ajudam a compreender nossas próprias práticas ético-teleológicas. Principalmente ao que concerne a ruptura e a transição entre esferas distintas de pensamento, quando da preocupação com a conduta humana saltou do polo coletivo, que visava o bem comum, ao polo individualizado autárquico ou, como o intitulado, egológico. Com efeito, as questões levantadas pelos filósofos gregos e seus desdobramentos helênicos ainda não encontraram uma resposta definitiva. Fato este que só acentua a sua importância, quanto ao desenvolvimento de uma investigação acerca da praxis humana como um todo.

\footnotetext{
${ }^{3}$ Grifo nosso.
} 


\section{Referências}

ABRÃO, Bernadete S. História da Filosofia. São Paulo: Nova Cultura LTDA, 2004.

ARISTÓTELES. A Política. Trad. Mário da Gama Cury. Brasília: Editora da UnB, 1985.

ARISTÓTELES. Ética a Nicômaco. Trad. Leonel Vallandro e Gerd Bornhein. Coleção Os Pensadores. $1^{\mathrm{a}}$ ed. São Paulo: Abril S.A. Cultural, 1984.

BAILLY, A. Dictionnaire Grec-Français. 16eme. Édition. Paris: Library Hachette, 1950.

EPICURO. Antologia de textos. Trad. Agostinho da Silva, Amador Cisneiros, Giulio Davide Leoni, Jaime Bruna. São Paulo: Abril Cultural, 1973.

EPICURO. Carta sobre a felicidade (a Meneceu). Trad. Álvaro L. e Enzo Del Carratore. São Paulo: UNESP, 2002.

FERREIRA, Aurélio Buarque de Holanda. Minidicionário da Língua Portuguesa. $3^{\text {a }}$ ed. Rio de Janeiro: Nova Fronteira, 1993.

GAZOLLA, Rachel. O ofício do filósofo estoico: o duplo discurso da Stoa. São Paulo: Loyola, 1999. LUZ, Ana Rosa. "A verdade como questão nota sobre a resposta fenomenológica à noção transcendental do criticismo". Revista Paranaense de Filosofia, vol. 1, Curitiba, p. 200-214, 2021. LUZ, Ana Rosa. "O Teleologismo de Aristóteles: A Teoria das Virtudes à luz da Ética a Nicômaco". Ítaca, vol. 27, Rio de Janeiro, p.78-93, 2015.

LUZ, Ana Rosa. "Reflexão Filosófica sobre a Bioética e a Técnica". Revista Eletrônica Do Vestibular, vol. 30, Rio de Janeiro, p.1-3, 2018.

PLATÃO. A República. Trad. Carlos Alberto Nunes. $3^{\text {a }}$ ed. Belém: EDUFPA, 2000.

Autor(a) para correspondência / Corresponding author: Ana Rosa Luz. luz.anarosa@yahoo.com.br 